\title{
РОЛЬ СПЕЦИАЛЬНЫХ НАЛОГОВЫХ РЕЖИМОВ В ФОРМИРОВАНИИ ДОХОДОВ РЕГИОНАЛЬНОГО БЮДЖЕТА
}

\author{
(c) 2018 Чотчаева Мадина Зулкарнаевна \\ кандидат экономических наук, доцент кафедры «Экономическая теория» \\ Северо-Кавказская государственная академия \\ 369000, г. Черкесск, ул. Ставропольская, д. 36 \\ E-mail: madinach@mail.ru \\ (c) 2018 Чотчаев Расул Зулкарнаевич \\ магистрант \\ Северо-Кавказская государственная академия \\ 369000, г. Черкесск, ул. Ставропольская, д. 36
}

В статье проведена оценка налоговых поступлений по специальным налоговым режимам в региональный бюджет на примере Карачаево-Черкесской республики, показана их роль в поддержке малого бизнеса путем снижения налоговых ставок, уменьшения налоговой базы или снижением количества уплачиваемых налогов. На конкретном статистическом материале рассмотрены начисления и поступления по основным видам налогов, администрируемых Федеральной налоговой службой Российской Федерации.

Ключевые слова: налоговые поступления, специальные налоговые режимы, консолидированный бюджет, региональный бюджет, Карачаево-Черкесская республика.

В соответствии с Налоговым кодексом Российской Федерации субъектам малого предпринимательства предоставлено право выбора одного из специальных режимов налогообложения - упрощенной системы налогообложения (УСН), системы налогообложения в виде единого налога на вмененный доход для отдельных видов деятельности (ЕНВД), патентной системы налогообложения (ПСН), системы налогообложения для сельскохозяйственных товаропроизводителей (ЕСХН).

Данные специальные режимы направлены на поддержку малого и среднего бизнеса. По сравнению с общей системой налогообложения, при специальном режиме происходит снижение налоговой нагрузки предприятия путем снижения налоговых ставок, уменьшения налоговой базы или снижением количества уплачиваемых налогов. Для того, чтобы говорить об эффективности того или иного налога необходимо проанализировать их динамку за последние три года и удельный вес каждого в общей структуре налоговых поступлений [4].

Рассмотрим начисления и поступления по основным видам налогов, администрируемых ФНС Российской Федерации за 2015-2017 годы (табл. 1).

В консолидированный бюджет Российской
Федерации в 2017 году поступило администрируемых ФНС РФ доходов в размере 17343,4 млрд. рублей, или на 19,8\% больше, чем в 2016 году. В общем объеме поступлений в консолидированный бюджет Российской Федерации в 2017 году удельный вес поступлений в федеральный бюджет составил 53\%, в консолидированные бюджеты субъектов Российской Федерации - 47\%. В 2016 году указанное соотношение составляло $48 \%$ и 52\% соответственно [3].

Налоговые платежи по совокупному доходу в консолидированный бюджет Российской Федерации в 2017 году составили 516,8 млрд. рублей, или на 5,4\% больше, чем в 2016 году, но на 9,8\% меньше чем, в 2015 году.

Поступления от специальных налоговых режимов зачисляются в местные бюджеты, за исключением упрощенной системы, в отношении которой субъекты Российской Федерации наделены правом закреплять нормативы отчислений за местными бюджетами. Так, по итогам 2016 года доходы от УСН муниципальным образованиям передавали 36 регионов, в том числе 15 регионов в размере не менее 50\% [2].

Поступления налогов на совокупный доход (налог, взимаемый при упрощенной системе налогообложения, единый налог на вмененный доход, единый сельскохозяйственный налог и 
Таблица 1. Поступления налогов и сборов в консолидированный бюджет РФ за 2015-2017 г.г., млрд. руб.

\begin{tabular}{|c|c|c|c|c|c|c|}
\hline \multirow[b]{2}{*}{ Наименование } & \multirow{2}{*}{$\begin{array}{l}2015 \text { г., } \\
\text { млрд.руб. }\end{array}$} & \multirow{2}{*}{$\begin{array}{c}2016 \text { г., } \\
\text { млрд.руб. }\end{array}$} & \multirow{2}{*}{$\begin{array}{l}2017 \text { г., } \\
\text { млрд.руб. }\end{array}$} & \multicolumn{3}{|c|}{ Темпы роста,\% } \\
\hline & & & & $\begin{array}{l}2016 \text { г. к } \\
2015 \text { г. }\end{array}$ & $\begin{array}{l}2017 \text { г. к } \\
2016 \text { г. }\end{array}$ & $\begin{array}{c}2017 \text { г. к } \\
2015 \text { г. }\end{array}$ \\
\hline Налог на прибыль организаций & 2598,8 & 2770,2 & 3290 & 106,6 & 118,8 & 126,6 \\
\hline Налог на доходы физических лиц & 2806,5 & 3017,3 & 3251,1 & 107,5 & 107,7 & 115,8 \\
\hline $\begin{array}{l}\text { НДС на товары (работы и услуги) реализуемые } \\
\text { на территории РФ }\end{array}$ & 2448,3 & 2657,4 & 3069,9 & 108,5 & 115,5 & 125,4 \\
\hline НДС на товары, ввозимые на территорию РФ & 141,7 & 150,8 & 166,4 & 106,4 & 110,3 & 117,4 \\
\hline $\begin{array}{l}\text { Акцизы по подакцизным товарам (продукции), } \\
\text { производимым на территории РФ }\end{array}$ & 1014,4 & 1293,9 & 1521,3 & 127,6 & 117,6 & 150 \\
\hline Налог на имущество физических лиц & 30,3 & 36,1 & 52,2 & 119,1 & 144,6 & 172,3 \\
\hline Налог на имущество организаций & 712,4 & 764,5 & 856,1 & 107,3 & 112 & 120,2 \\
\hline Транспортный налог & 140 & 139,1 & 154,9 & 99,4 & 111,4 & 110,6 \\
\hline Земельный налог & 185,1 & 176,4 & 186 & 95,3 & 105,4 & 100,5 \\
\hline Налог на добычу полезных ископаемых & 3226,8 & 2929,4 & 4130,4 & 90,8 & 141 & 128 \\
\hline Налоги на совокупный доход & 522,7 & 490,2 & 516,8 & 93,8 & 105,4 & 98,9 \\
\hline Иные поступления & 38,7 & 57,6 & 148,3 & 148,8 & 257,5 & 383,2 \\
\hline $\begin{array}{l}\text { Всего поступило в консолидированный бюджет } \\
\text { РФ }\end{array}$ & 13788,3 & 14482,9 & 17343,4 & 105 & 119,8 & 125,8 \\
\hline
\end{tabular}

Источник. Составлено по официальным данным ФНС РФ

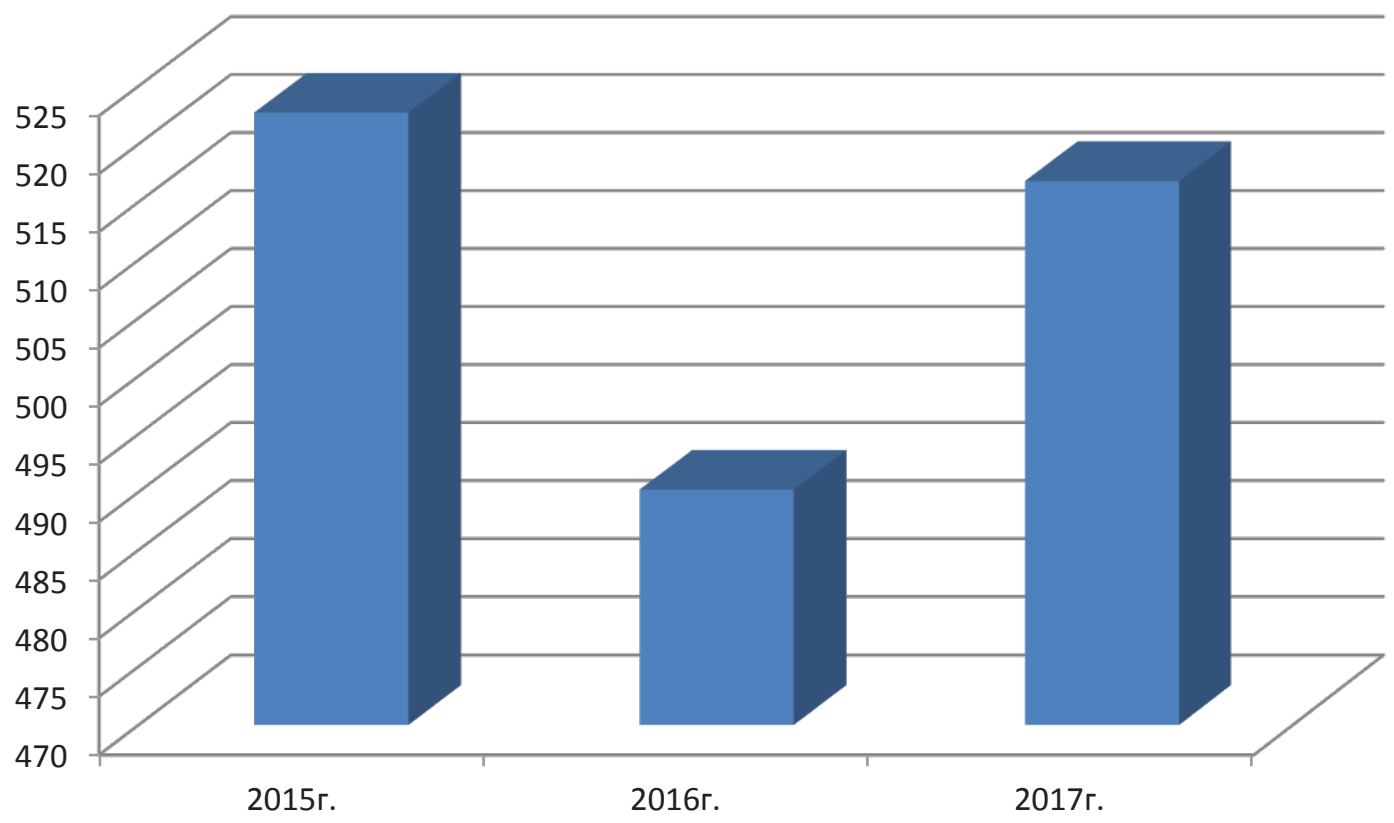

Рис.1. Поступления по налогам на совокупный доход в консолидированный бюджет РФ за 2015-2017 гг., млрд. рублей 
налог, взимаемый в связи с применением патентной системы налогообложения) в структуре консолидированных бюджетов субъектов РФ увеличились на $15,0 \%$, а доля этих налогов в общей сумме доходов консолидированных бюджетов субъектов РФ составила 4,2\% (3,9\% -в 2016 г.) [1]. Рассмотрим налоговые поступления в консолидированный бюджет Карачаево-Черкесской республики (табл.2).

На протяжении рассматриваемого периода налоговые поступления по специальным налоговым режимам имеют положительную динамику в 2016 году прирост составил 2,69\%, а в 2017 году $-8,68 \%$.

Наилучшая динамика наблюдается по упрощенной системе и единому сельскохозяйственному налогу. Так поступления по УСН выросли в 2016 г. на 3,29\%, а в 2017 году - на 11,24\% (табл.3).

В 2016 году по ЕСХН наблюдается максимальный прирост $-131,96 \%$, в 2017 году положительная динамика по данному режиму продолжилась, но в меньших масштабах- 66,92\% (табл.4).

Основную долю в налоговых поступлениях по специальным налоговым режимам в консолидированный бюджет Карачаево-Черкесской республики составляют налоговые доходы по упрощенной системе налогообложения - око- ло 70\% на протяжении всего периода. При этом наблюдается небольшой рост удельного веса по данному режиму с 69,71\% в 2015 году до 71,77\%, в 2017 году. Доля ЕСХН значительно выросла - с 2,7\% до 9,37\%. Отрицательная динамика наблюдается по ЕНВД и патентной системе налогообложения.

Рассмотрим налоговые поступления по упрощенной системе налогообложения зависимости от объекта налогообложения (табл.5).

Как указывалось выше, поступления по УСН носят положительный характер развития. Однако, при детальном рассмотрении поступлений по УСН видно, что по налогу, взимаемому с налогоплательщиков, выбравших в качестве объекта налогообложения «доходы, уменьшенные на величину расходов» в 2016 году произошел спад на 15,43\%. В 2017 году ситуация исправилась и рост составил 45,78\%. Наибольшей привлекательностью у налогоплательщиков в КЧР пользуется объект налогообложения - доходы. Привлекательность данного объекта налогообложения заключается в том, что нет необходимости подтверждать документально расходы. Поэтому организации и индивидуальные предприниматели выбирают данный объект налогообложения, несмотря на более высокую налоговую нагрузку.

Таблица 2. Поступления в консолидированный бюджет Карачаево-Черкесской республики за 2015-2017 г.г.

\begin{tabular}{|l|c|c|c|c|c|}
\hline \multicolumn{1}{|c|}{ Наименование } & 2015 г., & 2016 г., & 2017 г., & \multicolumn{2}{|c|}{ Темпы роста,\% } \\
\cline { 5 - 7 } & тыс.руб. & тыс.руб. & тыс.руб. & $\begin{array}{c}2016 \text { г. к } \\
2015 \text { г. }\end{array}$ & $\begin{array}{c}2017 \text { г. к } \\
2016 \text { г. }\end{array}$ \\
\hline Налоги на прибыль, доходы & 3977912 & 4846363 & 5071320 & 121,83 & 104,64 \\
\hline $\begin{array}{l}\text { Налоги на товары (работы, услуги), реализуемые на } \\
\text { территории Российской Федерации }\end{array}$ & 23009 & 35079 & 39513 & 152,46 & 112,64 \\
\hline Налоги на имущество & 1016383 & 1056751 & 1241464 & 103,97 & 117,48 \\
\hline $\begin{array}{l}\text { Налоги, сборы и регулярные платежи за пользова- } \\
\text { ние природными ресурсами }\end{array}$ & 40934 & 41431 & 42169 & 101,21 & 101,78 \\
\hline Государственная пошлина & 39720 & 53396 & 49462 & 134,43 & 92,63 \\
\hline $\begin{array}{l}\text { Неналоговые доходы, администрируемые налого- } \\
\text { выми органами }\end{array}$ & 3337 & 2415 & 3851 & 72,37 & 159,46 \\
\hline Платежи при пользовании природными ресурсами & 41 & 31 & 45 & 75,61 & 145,16 \\
\hline Штрафы, санкции, возмещение ущерба & 3296 & 2384 & 3806 & 72,33 & 159,65 \\
\hline Налоги на совокупный доход & 345145 & 354417 & 385183 & 102,69 & 108,68 \\
\hline $\begin{array}{l}\text { Поступило налогов, сборов, иных обязательных } \\
\text { платежей в консолидированный бюджет Кчр }\end{array}$ & 5446232 & 6389285 & 6832723 & 117,32 & 106,94 \\
\hline
\end{tabular}

Составлено по официальным данным Министерство финансов РФ. 
Таблица 3. Налоговые поступления по специальным налоговым режимам в консолидированный бюджет Карачаево-Черкесской республики за 2015-2017 г.г.

\begin{tabular}{|c|c|c|c|c|c|c|c|}
\hline \multirow{2}{*}{ Наименование } & \multirow{2}{*}{$\begin{array}{l}2015 \text { г., } \\
\text { тыс.руб }\end{array}$} & \multirow{2}{*}{$\begin{array}{l}2016 \text { г., } \\
\text { тыс.руб }\end{array}$} & \multirow{2}{*}{$\begin{array}{l}2017 \text { г., } \\
\text { тыс.руб }\end{array}$} & \multicolumn{2}{|c|}{$\begin{array}{c}\text { Абсолютное откло- } \\
\text { нение, тыс.руб. }\end{array}$} & \multicolumn{2}{|c|}{ Темпы роста,\% } \\
\hline & & & & $\begin{array}{c}2016 \text { г. к } \\
2015 \text { г. }\end{array}$ & $\begin{array}{l}2017 \text { г. к } \\
2016 \text { г. }\end{array}$ & $\begin{array}{l}2016 \text { г. к } \\
2015 \text { г. }\end{array}$ & $\begin{array}{c}2017 \text { г. К } \\
2016 \text { г. }\end{array}$ \\
\hline $\begin{array}{l}\text { Налог, взимаемый в связи с примене- } \\
\text { нием упрощенной системы налогоо- } \\
\text { бложения }\end{array}$ & 240615 & 248526 & 276460 & 7911 & 27934 & 103,29 & 111,24 \\
\hline $\begin{array}{l}\text { Единый налог на вмененный доход для } \\
\text { отдельных видов деятельности }\end{array}$ & 94173 & 83558 & 72278 & -10615 & -11280 & 88,73 & 86,50 \\
\hline Единый сельскохозяйственный налог & 9324 & 21628 & 36102 & 12304 & 14474 & 231,96 & 166,92 \\
\hline $\begin{array}{l}\text { Налог, взимаемый в связи с примене- } \\
\text { нием патентной системы налогообло- } \\
\text { жения }\end{array}$ & 1033 & 705 & 343 & -328 & -362 & 68,25 & 48,65 \\
\hline Итого & 345145 & 354417 & 385183 & 9272 & 30766 & 102,69 & 108,68 \\
\hline
\end{tabular}

Источник. Составлено по официальным данным Министерство финансов РФ.

Таблица 4. Структура налоговых поступлений по специальным налоговым режимам в консолидированный бюджет Карачаево-Черкесской республики за 2015 г.-2017 г.

\begin{tabular}{|l|c|c|c|c|c|}
\hline \multicolumn{1}{|c|}{ Наименование } & & & & \multicolumn{2}{|c|}{ Абсолютное отклоне- } \\
\cline { 3 - 6 } & 2015 г. & 2016 г. & 2017 г. & $\begin{array}{c}2016 \text { г. к } \\
2015 \text { г. }\end{array}$ & $\begin{array}{c}2017 \text { г. к } \\
2016 \text { г. }\end{array}$ \\
\hline $\begin{array}{l}\text { Налог, взимаемый в связи с применением } \\
\text { упрощенной системы налогообложения }\end{array}$ & 69,71 & 70,12 & 71,77 & 0,41 & 1,65 \\
\hline $\begin{array}{l}\text { Единый налог на вмененный доход для отдельных } \\
\text { видов деятельности }\end{array}$ & 27,29 & 23,58 & 18,76 & $-3,71$ & $-4,81$ \\
\hline Единый сельскохозяйственный налог & 2,70 & 6,10 & 9,37 & 3,40 & 3,27 \\
\hline $\begin{array}{l}\text { Налог, взимаемый в связи с применением } \\
\text { патентной системы налогообложения }\end{array}$ & 0,30 & 0,20 & 0,09 & $-0,10$ & $-0,11$ \\
\hline Итого & 100,00 & 100,00 & 100,00 & 0 & 0 \\
\hline
\end{tabular}

Источник. Составлено по официальным данным Министерство финансов РФ.

Таблица 5. Распределение налоговых поступлений по упрощенной системе налогообложения в консолидированный бюджет КЧР за 2015-2017 гг.

\begin{tabular}{|l|c|c|c|c|c|c|c|}
\hline \multicolumn{1}{|c|}{ Наименование } & 2015 г., & 2016 г., & 2017 г., & \multicolumn{2}{|c|}{$\begin{array}{c}\text { Абсолютное откло- } \\
\text { нение, тыс.руб. }\end{array}$} & \multicolumn{2}{|c|}{ Темпы роста,\% } \\
\cline { 5 - 8 } & тыс.руб. & тыс.руб. & тыс.руб. & $\begin{array}{c}2016 \text { г. к } \\
2015 \text { г. }\end{array}$ & $\begin{array}{c}2017 \text { г. к } \\
2016 \text { г. }\end{array}$ & $\begin{array}{c}2016 \text { г. к } \\
2015 \text { г. }\end{array}$ & $\begin{array}{c}2017 \text { г. к } \\
2016 \text { г. }\end{array}$ \\
\hline $\begin{array}{l}\text { Налог, взимаемый с налогоплатель- } \\
\text { щиков, выбравших в качестве объекта } \\
\text { налогобложения доходы }\end{array}$ & 145418 & 161458 & 175395 & 16040 & 13937 & 111,03 & 108,63 \\
\hline $\begin{array}{l}\text { Налог, взимаемый с налогоплательщи- } \\
\text { ков, выбравших в качеств объекта на- } \\
\text { логообложения доходы, уменьшенные } \\
\text { на величину расходов }\end{array}$ & 82901 & 70111 & 102208 & -12790 & 32097 & 84,57 & 145,78 \\
\hline
\end{tabular}

Источник. Составлено по официальным данным Министерство финансов РФ. 


\section{Библиографический список}

1. Анализ тенденций в бюджетно-налоговой сфере России// Аналитический бюллетень РЭУ им.Г.В.Плеханова https://www.rea.ru/ru.

2. Доклад о достигнутых результатах по улучшению условий ведения предпринимательской деятельности, развитию малого и среднего бизнеса и поддержке индивидуальной предпринимательской инициативы http://economy.gov.ru/wps/wcm/connect/c5262b2b-2833-4be9-bcc9.

3. Справка «О поступлении администрируемых ФНС России доходов в 2017 году» — https://analytic.nalog.ru/ portal/index.ru-RU.htm.

4. Тищенко E.C., Сташ 3.Н., Уколова А.С. Совершенствование практики применения специальных налоговых режимов в РФ // Экономика и предпринимательство.2016. № 8 (73). С. 100-105.

Поступила в редакцию 21.12.2018 